\title{
Effects of single-dose morning and evening administration of pravastatin on antioxidant markers in cholesterol-fed rabbits
}

This article was published in the following Dove Press journal:

Journal of Experimental Pharmacology

12 May 2011

Number of times this article has been viewed

\author{
Sahar Mohamed Kamal \\ Department of Pharmacology, Faculty \\ of Medicine, Ain Shams University, \\ Cairo, Egypt
}

Background: Accurate timing of statin administration is considered important to obtain the best hypolipidemic effect. Pravastatin is one of the currently prescribed hepatic 3-hydroxy-3-methylglutaryl coenzyme A reductase inhibitors, and was chosen in this study to evaluate its antioxidant effect when administered as a single daily dose in the morning versus evening in cholesterol-fed rabbits.

Methods: This 12-week study was performed in New Zealand rabbits, divided into four groups ( $n=6$ each), ie, normocholesterolemic controls; cholesterol 1\% diet, nontreated ; cholesterol 1\% diet treated with pravastatin in the morning; and cholesterol $1 \%$ diet treated with pravastatin in the evening. Plasma total cholesterol levels, superoxide dismutase enzyme levels in erythrocyte lysates, thiobarbituric acid-reactive substance content, catalase, and glutathione enzyme activity in liver homogenates from the tested rabbits were measured.

Results: Both morning and evening treatment with pravastatin significantly improved all the measured antioxidant markers in comparison with nontreated cholesterol-fed rabbits. However, results obtained with evening dosing were better than with morning dosing.

Conclusion: The antioxidant profile of pravastatin is better when the drug is administered in the evening rather than in the morning.

Keywords: pravastatin, chronotherapy, antioxidant markers, cholesterol-fed rabbits

\section{Introduction}

There is a strong correlation between elevated serum cholesterol levels and the incidence of atherosclerosis. ${ }^{1}$ Dyslipidemia (high level of low-density lipoprotein [LDL] and/or low levels of high-density lipoprotein [HDL]) initially causes injury to the arterial endothelium. ${ }^{1,2}$ Endothelial dysfunction allows accumulation of lipoproteins in the subendothelial space, where chemical modification of LDL can occur. Modified LDL recruits monocytes into the vessel wall, where these cells are converted to macrophages that engulf the modified lipoproteins and become foam cells. ${ }^{3}$ Many of the manifestations of atherosclerosis are likely secondary to the actions of superoxide reactive oxygen species that increase in body organs and in the vascular wall in association with the atherosclerotic process. ${ }^{4}$ The sources of reactive oxygen species, whether in normal or in pathological situations, are not fully understood, but there is some evidence that xanthine oxidase, nitric oxide synthase, leukocyte NAD $(\mathrm{P}) \mathrm{H}$ oxidase, and vascular NAD(P)H oxidase are the main contributors to the generation of reactive oxygen species in body tissue. ${ }^{5}$ Nitric oxide is thought to preserve the integrity of the endothelium and may prevent atherosclerosis. ${ }^{6}$ The protective role of nitric oxide is supported to a large extent by superoxide dismutase, an enzyme that has an
Correspondence: Sahar Mohamed Kamal Department of Pharmacology, Faculty of Medicine, Ain Shams University, Cairo, Egypt

Tel +20224186992

$\mathrm{Fax}+20224186992$

Email saharkamal2003@hotmail.com 
important antioxidant effect through both the protection of nitric oxide against inactivation by reactive oxygen species and the prevention of lipid peroxidative damage to cells. ${ }^{7}$

Reduction of plasma cholesterol is usually associated with a decrease in the mortality rate due to coronary heart disease. ${ }^{8}$ Hepatic 3-hydroxy-3-methylglutaryl coenzyme A (HMG-CoA) reductase plays a crucial role in cholesterol biosynthesis because it catalyzes the rate-limiting step via formation of mevalonic acid. Competitive inhibition of hepatic HMG-CoA reductase by agents commonly known as statins reduces hepatocyte cholesterol concentrations and triggers increased expression of hepatic LDL receptors. This, in turn, clears LDL and LDL precursors from the circulation. ${ }^{9}$ In addition to lowering cholesterol levels, statins also inhibit hepatic synthesis of apolipoprotein B-100 and decrease synthesis and secretion of triglyceride-rich lipoproteins. ${ }^{10}$ Furthermore, statins exert a protective effect against stroke by increasing production of endothelial nitric oxide synthase rather than by a cholesterol-lowering effect. ${ }^{11}$

Cholesterol biosynthesis follows a circadian rhythm in which higher rates of hepatic cholesterol formation occur during the evening hours, even in the fasting state. ${ }^{12}$ Long-term treatment with pravastatin exerts an antioxidative and antiinflammatory effect in OLETF rats (an animal model of type 2 diabetes mellitus) that improves diabetes and minimizes pancreatic fibrosis. ${ }^{13}$ This effect may depend on duration of treatment with correct daily timing of administration in order to obtain the best antioxidative profile, and this needs further investigation in animal models of hypercholesterolemia.

According to The National Cholesterol Education Program Adult Treatment Panel III, statins are the recommended first-line therapy for lowering LDL cholesterol levels. Given that cholesterol is biosynthesized in the early morning hours, the US Food and Drug Administration (FDA) has recommended evening administration for statins with shorter halflives (lovastatin 2 hours, simvastatin less than 5 hours, and fluvastatin less than 3 hours). In contrast, the FDA suggests day time administration for statins with longer half-lives (atorvastatin 14 hours, rosuvastatin 19 hours, and pravastatin 22 hours). Atorvastatin also has active metabolites, with half-lives ranging from 20-30 hours, which may contribute to the fact that it can be taken at any time. ${ }^{14}$

In our review of the literature, the only statistically significant finding was that simvastatin should be taken in the evening to optimize reduction of LDL cholesterol levels. Most of the chronobiologic studies conducted in hyperlipidemic patients failed to provide statistically significant data. The reasons for this is likely related to the lack of large sample sizes or disorders in the statistical analysis and study design, especially with regard to the exclusion criteria which may have resulted in some confounding factors. Clinicians are still looking for continuous prospective, randomized trials with larger samples of hyperlipidemic patients to reach definitive conclusions about the ideal timing of statin administration. In the meantime, some authors have concluded that the available evidence supports evening administration of lovastatin and fluvastatin (as well as simvastatin), and day time administration of pravastatin, rosuvastatin, and atorvastatin, for maximal lowering of LDL. ${ }^{14}$

In an attempt to clarify these issues, the present study investigated whether there is any difference in effect between morning and evening administration of a single dose of pravastatin on plasma total cholesterol levels and antioxidant markers (ie, thiobarbituric acid-reactive substance [TBARS] content), as well as on the activity of catalase and glutathione peroxidase enzymes in liver homogenates of cholesterol-fed rabbits. Superoxide dismutase enzyme activity was also measured in red blood cell lysates as an index of the antioxidant state for the two different times of drug administration. Our results may help to identify a strategy of chronotherapy for pravastatin in order to obtain the best hypolipidemic and antioxidative effects of the drug.

\section{Materials and methods}

Pravastatin sodium was sourced from Bristol-Myers Squibb Co (New York, NY), spectrophotometric assay kits for measurement of plasma total cholesterol levels from BoehringerMannheim (Mannheim, Germany), and for measurement of superoxide dismutase enzyme from Randox Laboratories (Crumlin, UK). All other chemicals were obtained from Sigma Chemical Co (St Louis, MO). The powdered drug

Table I Changes in the activity of liver catalase and glutathione peroxidase

\begin{tabular}{lcc}
\hline Group & $\begin{array}{l}\text { Catalase Unit }{ }^{\mathrm{a}} / \mathrm{mg} \\
\text { tissue protein }\end{array}$ & $\begin{array}{l}\text { Glutathione } \\
\text { peroxidase } \\
\text { Unit } / \mathbf{m g} \text { tissue } \\
\text { protein }\end{array}$ \\
\hline $\begin{array}{l}\text { Control (Group I) } \\
\begin{array}{l}\text { Cholesterol-fed nontreated } \\
\text { group (Group 2) }\end{array}\end{array}$ & $\begin{array}{l}70.45 \pm 2.48 \pm 0.74^{*} \\
\begin{array}{l}\text { Cholesterol-fed, morning } \\
\text { pravastatin group (Group 3) }\end{array}\end{array}$ & $0.82 \pm 0.06^{*}$ \\
$\begin{array}{l}\text { Cholesterol-fed, evening } \\
\text { pravastatin group (Group 4) }\end{array}$ & $69.35 \pm 2.90 \pm 2.73^{* *, \dagger}$ & $8.93 \pm 0.5^{* *}$ \\
\hline
\end{tabular}

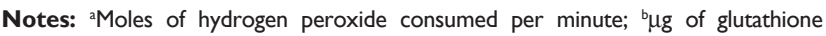
consumed per minute. $* P<0.05$, significant reduction in activity of both enzymes versus Group I; **P $<0.05$, significant increase in activity of both enzymes versus Group 2; ${ }^{\dagger} P<0.05$, significant increase in activity of both enzymes versus Group 3. 
was dissolved in methanol and this was freshly prepared throughout the study. An earlier pilot study undertaken to exclude any confounding effect of the solvent showed no effect of administration of methanol alone on the parameters tested in this study in a group of cholesterol-fed rabbits.

Twenty-four male New Zealand rabbits were randomly divided into four groups, six rabbits each: All groups were maintained on noncholesterol-fortified feed for 3 weeks before the start of the study to ensure the proper matching of their baseline total plasma cholesterol level and to be acclimatized to the laboratory's conditions. Then, the experiments started from the beginning of the fourth week to the end of the twelfth week as follows:

Group 1: Control group continued to be fed a noncholesterol-fortified feed for 8 weeks.

Group 2: Cholesterol-fed diet (1\% w/w) for 8 weeks.

Group 3: Pravastatin morning-treated cholesterol-fed diet $(1 \% \mathrm{w} / \mathrm{w})$ for 8 weeks.

Group 4: Pravastatin evening-treated cholesterol-fed diet $(1 \% \mathrm{w} / \mathrm{w})$ for 8 weeks.

Pravastatin was administered orally in a single dose of $5 \mathrm{mg} / \mathrm{kg}$ from the beginning of the fourth week to the end of the twelfth week for Group 3 (at 8 am daily) and for Group 4 (at 8 pm daily). The drug was dissolved in methanol and applied to cabbage leaves, the methanol subsequently evaporated and the drug was left as a coating layer on the leaf. It was fed to the rabbits and was usually eaten immediately and completely.

All laboratory measurements were performed at the end of the experiments (the end of the twelfth week) except the total plasma cholesterol level, which was done initially, at the end of the fourth week (considered to be the first week of the experiment), and then at the end of both the eighth and twelfth weeks.

The dose of pravastatin used in this study was selected in view of data previously reported by Ueda et al. ${ }^{15}$ This dose was also tested in a pilot study and showed promising results using the parameters tested in the present study. Our selection of the morning and evening doses was based on the results of another pilot study performed to identify the optimal timing to answer the research question. All procedures were in accordance with the National Institute of Health's Guide for the Care and Use of Laboratory Animals, as well as the guidelines of the Animal Welfare Act.

\section{Plasma total cholesterol levels}

Plasma total cholesterol levels were measured at baseline and at the end of weeks 4,8 , and 12 , using commercially available spectrophotometric assay kits, with the results expressed in $\mathrm{mg} / \mathrm{dL}$.

\section{Superoxide dismutase in erythrocyte lysates}

At the end of week 12, blood samples were collected from the rabbits in all four groups for the measurement of superoxide dismutase levels in erythrocyte lysates, using commercially available colorimetric assay kits, and an indirect xanthinexanthine oxidase method, as described by Halliwell and Chirico, ${ }^{16}$ with the results expressed in IU/mL.

\section{Hepatic lipid peroxidation}

Hepatic lipid peroxidation was quantified by measuring TBARS according to the method described by Fraga et al. ${ }^{17}$ Liver tissue from each rabbit was homogenized in nine volumes of $50 \mathrm{mmol} / \mathrm{L}$ Tris- $\mathrm{HCl}$ buffer $(\mathrm{pH} 7.4$ ) containing $180 \mathrm{mmol} / \mathrm{L} \mathrm{KCl}, 10 \mathrm{mmol} / \mathrm{L}$ ethylenediamine tetra-acetic acid, and $0.02 \%$ butylated hydroxytoluene. To $0.2 \mathrm{~mL}$ of tissue homogenate, $0.2 \mathrm{~mL}$ of $8.1 \%$ sodium dodecyl sulfate, $1.5 \mathrm{~mL}$ of $20 \%$ acetic acid, $1.5 \mathrm{~mL}$ of $0.9 \%$ thiobarbituric acid, and $0.6 \mathrm{~mL}$ of distilled water were added and vortexed. The reaction mixture was placed in a water bath at $95^{\circ} \mathrm{C}$ for 1 hour. After cooling on ice, $1.0 \mathrm{~mL}$ of distilled water and $5.0 \mathrm{~mL}$ of butanol/pyridine mixture $(15: 1, \mathrm{v} / \mathrm{v})$ were added and vortexed. After centrifugation at $10,000 \times \mathrm{g}$ for 10 minutes, absorbance of the resulting precipitate was determined at $532 \mathrm{~nm}$. The TBARS concentration was calculated using 1,1,5,5-tetraethoxypropane as standard.

\section{Catalase enzyme activity}

Catalase activity in the liver homogenates was assayed colorimetrically according to the method described by Bradford, ${ }^{18}$ using dichromate-acetic acid reagent (5\% potassium dichromate and glacial acetic acid mixed in a 1:3 ratio). Intensity was measured at $620 \mathrm{~nm}$, and the amount of hydrogen peroxide hydrolyzed was calculated for the catalase activity.

\section{Glutathione peroxidase enzyme activity}

Glutathione peroxidase activity in the liver homogenates was measured using the method described by Sinha. ${ }^{19}$ Activity was expressed based on inhibition of glutathione.

\section{Protein determination}

The protein content of the liver homogenates was determined by spectrophotometry according to the method of Rotruck et al. ${ }^{20}$ The aim was to express the TBARS 


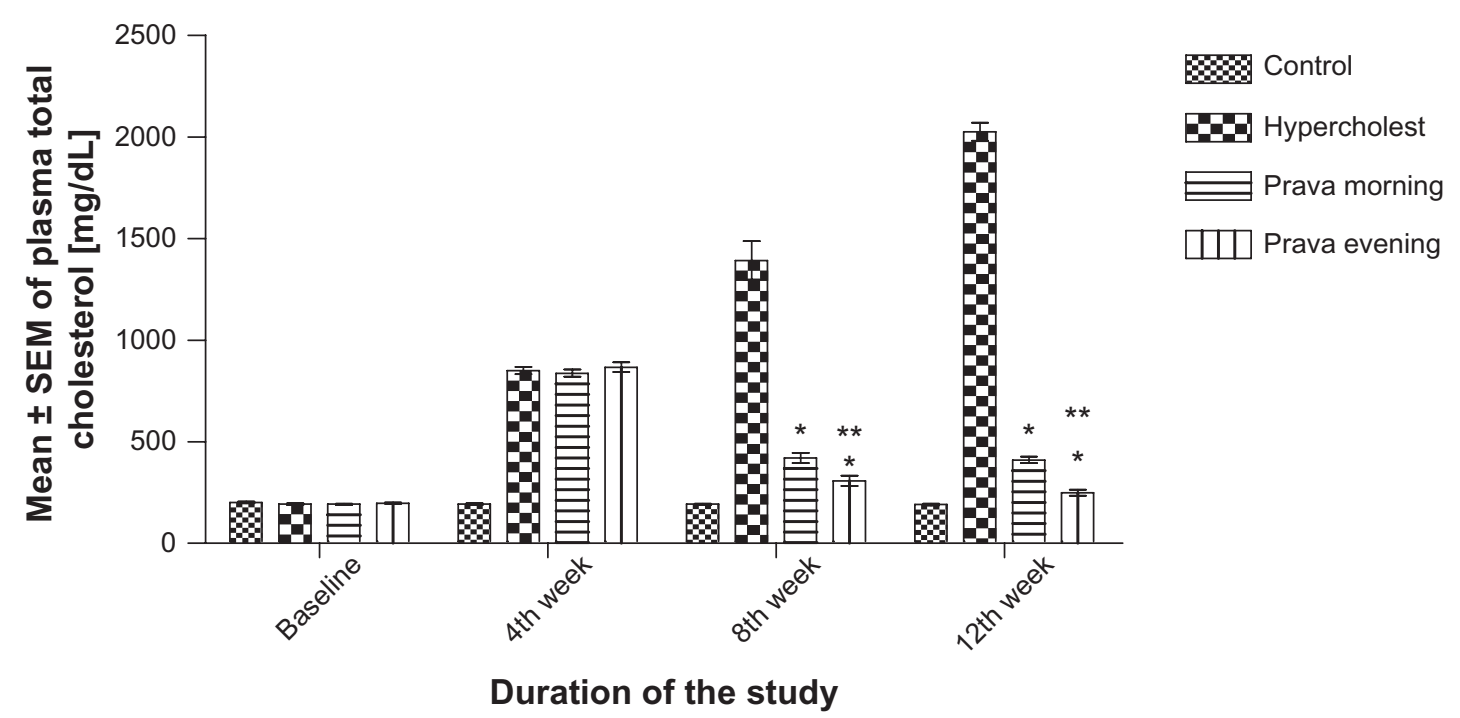

Figure I Effect of 8-weeks administration of pravastatin on plasma total cholesterol level in the tested rabbits.

Notes: Results are expressed as mean \pm SEM ( $n=6$ rabbits/group). Both morning and evening administration significantly ( $\mathrm{P}<0.05)$ decreased plasma total cholesterol levels in comparison to the hypercholesterolemic Group 2. However, significant ("P< $<.05$ ) results obtained with Group 4 (evening treatment) when compared to Group 3 (morning treatment).

concentration as $\mathrm{nmol} / \mathrm{mg}$ tissue protein, and catalase and glutathione peroxidase enzyme activity as Unit/mg tissue protein.

\section{Statistical analysis}

Results are expressed as mean \pm standard error of the mean. Statistical analysis was performed by analysis of variance, followed by Bonferroni's post hoc test using GraphPad Prism (v 3.00 for Windows 97; Graph Pad Software, San Diego, CA). Differences with $P<0.05$ were considered to be statistically significant.

\section{Results \\ Effect of pravastatin on plasma total cholesterol levels}

Figure 1 shows that administration of pravastatin $5 \mathrm{mg} / \mathrm{kg} /$ day for 8 weeks to hypercholesterolemic rabbits, whether given in the morning (Group 3) or evening (Group 4), significantly $(P<0.05)$ decreased plasma cholesterol levels in comparison with the results obtained in nontreated hypercholesterolemic rabbits (Group 2). Evening pravastatin (Group 4) was significantly $(P<0.05)$ more effective than morning pravastatin (Group 3) in decreasing plasma total cholesterol levels.

\section{Effect of pravastatin on superoxide dismutase enzyme}

Induction of hypercholesterolemia in nontreated hypercholesterolemic rabbits (Group 2) almost depleted superoxide dismutase enzyme activity in erythrocytes, but did not do so in the controls (Group 1) (Figure 2). Morning pravastatin restored $67.45 \%$ of control superoxide dismutase enzyme levels (23.42 $\pm 2.4 \mathrm{IU} / \mathrm{mL}$ [Group 3] versus $34.72 \pm 0.73$ $\mathrm{IU} / \mathrm{mL}$ [Group 1], $P<0.05)$. Evening pravastatin restored $189.94 \%$ of control levels $(65.95 \pm 2.54 \mathrm{IU} / \mathrm{mL}$ [Group 4] versus $34.72 \pm 0.73 \mathrm{IU} / \mathrm{mL}$ [Group 1], $P<0.05$ ). The increase in superoxide dismutase enzyme levels was significantly $(P<0.05)$ greater with evening treatment (Group 4) than with morning treatment (Group 3).

\section{Effect of pravastatin on hepatic lipid peroxidation}

The nontreated cholesterol-fed rabbits (Group 2) had significantly elevated lipid peroxide levels $(P<0.05)$, expressed as TBARS in $\mathrm{nmol} / \mathrm{mg}$ tissue protein from liver homogenates in comparison with controls (Group 1) (Figure 3). On the other hand, daily treatment with morning or evening pravastatin for 8 weeks significantly $(P<0.05)$ lowered hepatic TBARS levels in comparison with nontreated hypercholesterolemic rabbits (Group 2). Reduction in this marker was significantly $(P<0.05)$ greater in rabbits receiving evening pravastatin (Group 4), to a level comparable with that in the controls.

\section{Effect of pravastatin on the activities of liver catalase and glutathione peroxidase}

Table 1 shows a significant decrease in the activities of enzymic antioxidants in cholesterol-fed nontreated rabbits. The treated Groups $3 \& 4$ showed that the activities 


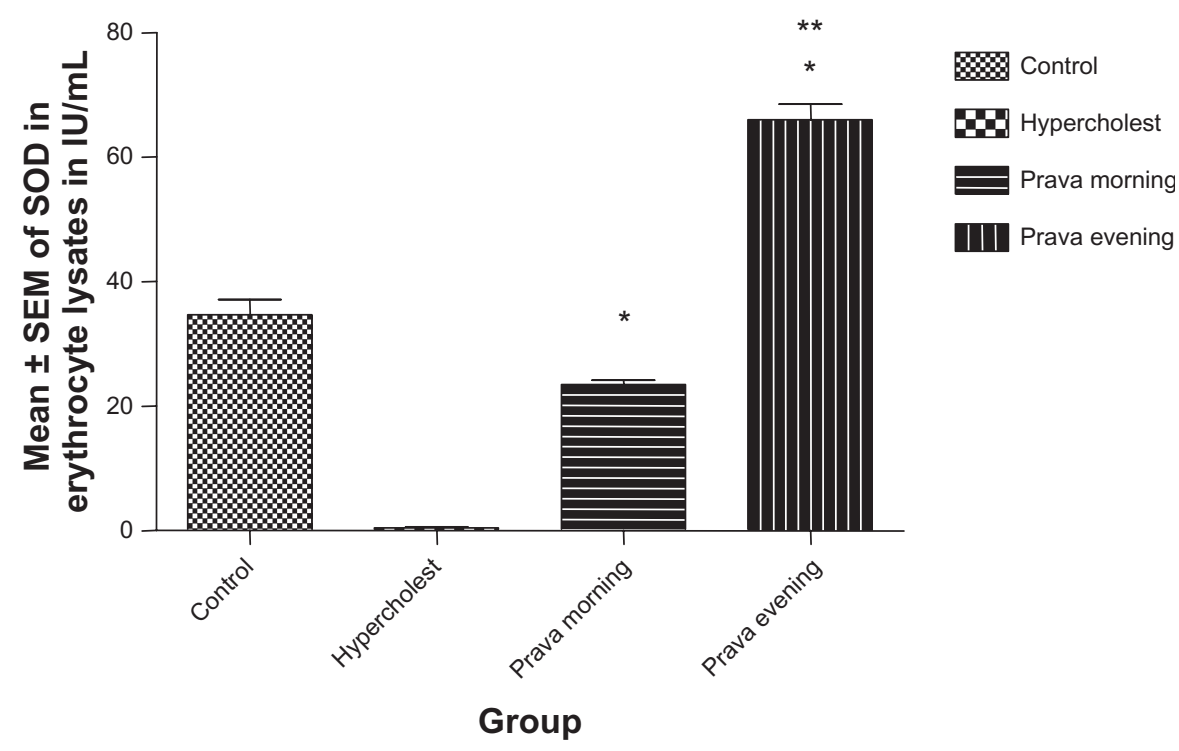

Figure 2 Effect of 8-weeks administration of pravastatin on superoxide dismutase [SOD] enzyme in IU/mL of erythrocyte lysates of the tested rabbits.

Notes: Effect of morning and evening single dose administration of pravastatin on the SOD enzyme levels in the erythrocyte lysates obtained from the four tested groups of rabbits. Results are expressed as mean \pm SEM ( $n=6$ rabbits/group). Both morning and evening administration significantly (*P $<0.05)$ increased SOD enzyme levels in comparison to the hypercholesterolemic Group 2. However, significant (**P $<0.05$ ) results were obtained with Group 4 (evening treatment) when compared to Group 3 (morning treatment).

of enzymic antioxidants were significantly reversed to near normal, especially with evening drug administration. Group 4 (prava-evening treated group) showed a significant increase of activities of the tested enzymes to values higher than that recorded in Group 3 (prava-morning treated group) and close to that recorded in the control group. This suggests a higher antioxidant benefit induced by evening administration of this statin.

\section{Discussion}

Hypercholesterolemia is an alarming health problem that leads to atherogenesis and serious complications, especially

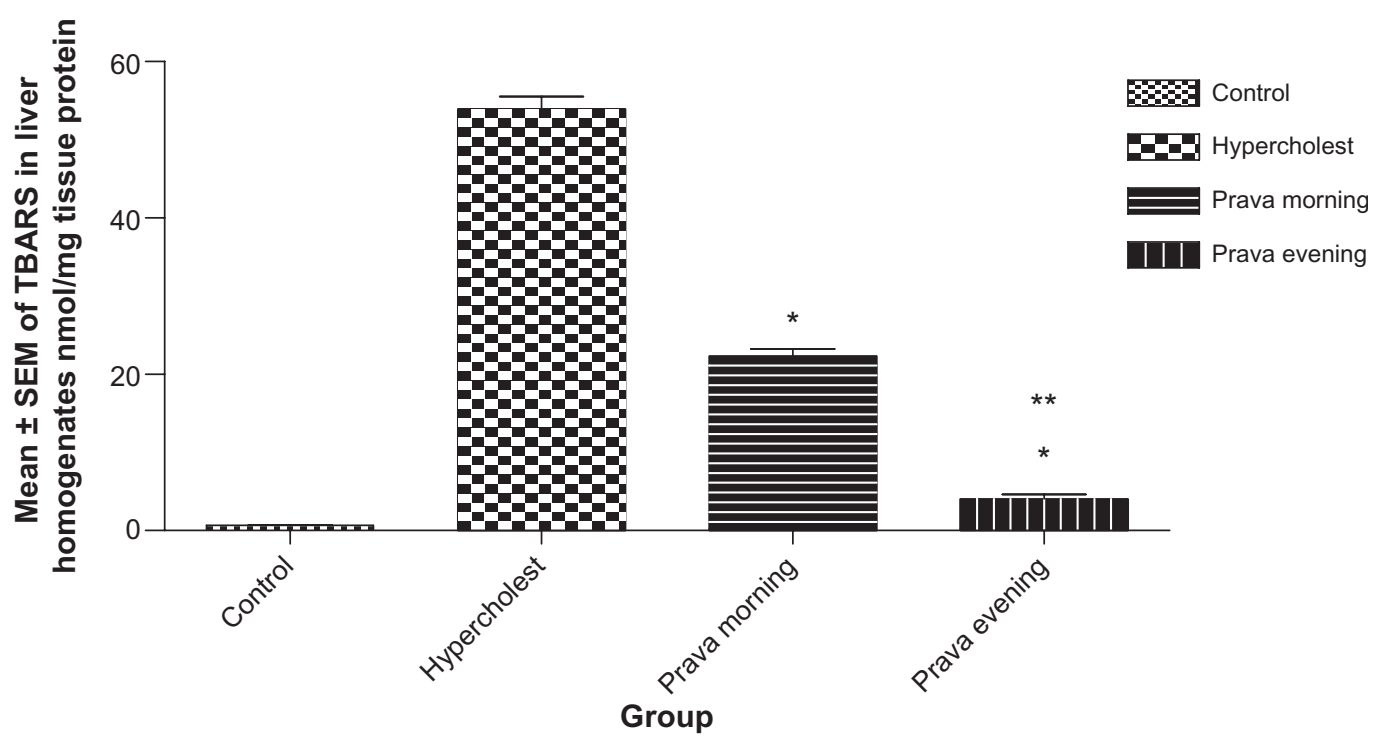

Figure 3 Effect of 8-weeks administration of Pravastatin on thiobarbituric acid-reactive substance (TBARS) in nmol/mg tissue protein of the liver tissue homogenates of the Tested Rabbits.

Notes: Effect of treatment with pravastatin on the level of lipid peroxide expressed as thiobarbituric acid-reactive substance (TBARS) in nmol/mg tissue protein in liver tissue homogenates of the four tested groups of rabbits. Results are expressed as mean \pm SEM ( $n=6$ rabbits/group). Both morning and evening administration significantly $(* P<0.05)$ decreased TBARS levels in comparison to the hypercholesterolemic Group 2 . However, a more significant $(* * P<0.05)$ reduction in this marker was reported with the evening treatment (Group 4) compared to the morning treatment (Group 3). 
myocardial infarction and cerebral stroke. One of the harmful early sequelae of hypercholesterolemia is endothelial cell dysfunction, ${ }^{21,22}$ contributing to the development of overt atherosclerosis. There has been a suggestion that decreased availability of nitric oxide in the vascular endothelium predisposes to coronary artery disease and various organ disturbances. ${ }^{21,23}$ This suggestion has prompted a large number of experimental and clinical studies of the importance of oxidative stress in the development of many diseases, especially cardiovascular disease and atherosclerosis. The advent of the HMG-CoA reductase inhibitors, commonly known as statins, introduced an excellent pharmacological tool for the management of hyperlipidemia. Statins reversibly block the rate-limiting step of cholesterol biosynthesis in the liver, ${ }^{24}$ and significantly decrease the risk of coronary heart disease, primarily by lowering LDL cholesterol levels and slightly elevating HDL cholesterol levels. ${ }^{25}$ The early recommendations for use of statins in the management of hypercholesterolemia included morning administration. However, this strategy was re-evaluated in light of reports showing that biosynthesis of cholesterol shows diurnal periodicity, with nocturnal increases in the level of cholesterol precursors. ${ }^{12,26}$ Clinical studies have also emphasized a need to identify the optimal time of day for administering statins, given that many patients being treated for hypercholesterolemia will also be receiving treatment for other cardiovascular disorders, and compliance may be compromised by multiple dosing. ${ }^{27}$

The present study showed that daily single-dose pravastatin administration for eight weeks in hyperlipidemic rabbits, whether administered in the morning or in the evening, significantly reduced plasma cholesterol levels, elevated superoxide dismutase levels in erythrocyte lysates, reduced TBARS content, and increased the activity of catalase and glutathione peroxidase enzymes in liver homogenates. Interestingly, all these beneficial effects were statistically significant when pravastatin was administered in the evening rather than in the morning.

The antioxidant effect of pravastatin was demonstrated in a study by Alanaz ${ }^{28}$ who loaded erythrocytes with primaquine, a compound known to damage erythrocytes via production of free radicals. Alanaz reported that statins have an antioxidant and protective effect in situations of oxidative stress, and suggested that the protective effect of pravastatin against primaquine-induced oxidative damage in human erythrocytes needed to be investigated further. In that study, animals treated with pravastatin showed some biomarkers of oxidative stress (nonprotein thiols, protein carbonyl, TBARS) present at levels similar to that in the controls. Reduction of protein oxidation and lipid peroxidation by pravastatin is related to the antioxidant effect of this statin. Preservation of erythrocyte fragility and morphology by pravastatin is related to its free radical scavenging action. This study concluded that pravastatin has a protective effect against erythrocyte dysfunction related to situations associated with increased oxidative stress, especially when loaded with primaquine. ${ }^{28}$

Another experimental study showed that long-term treatment with pravastatin suppresses apoptosis in the pancreas, because the single-strand DNA index in acinar cells was markedly reduced. ${ }^{13}$ In support of this observation, long-term treatment with pravastatin significantly increased pancreatic weight and its DNA and protein contents compared with a control group of OLETF rats. Because oxidative stress ${ }^{29}$ and inflammatory mediators, such as transforming growth factor- $\beta 1$ and tumor necrosis factor- $\alpha,{ }^{30}$ strongly induce apoptosis, it seems that pravastatin could inhibit apoptosis via its antioxidative and anti-inflammatory actions. ${ }^{31}$

Diurnal variation in apoptosis was observed in the small intestinal mucosa of Mongolian gerbils but disappeared after feeding, drinking, and ambulation. ${ }^{32}$ This observation could be the basis for further investigations concerning the link between possible diurnal changes in the pattern of apoptosis and the pronounced antioxidant effect of statins, including pravastatin, when administered in the evening. This type of study could be carried out in a similar way to research concerning the effects of diurnal irradiation and apoptosis. This research reported a two-fold increase in apoptosis during day time irradiation compared with night time irradiation. ${ }^{33}$

However, the crucial interesting observation that evening administration of pravastatin achieved more significant lowering of blood cholesterol, augmenting red blood cell levels of superoxide dismutase enzyme, reducing TBARS, and increasing catalase and glutathione peroxidase enzyme activity in liver homogenates, could be initially explained on the basis of more cholesterol biosynthesis at night than in the morning. In the absence of evening administration of pravastatin, plasma cholesterol levels would increase markedly, resulting in overt cholesterol deposition in vessel tissues, with consequent overproduction of reactive oxygen species. The latter would exhaust superoxide dismutase in the antioxidant process on the one hand and inactivate biologically available nitric oxide on the other, with a resulting deterioration in vascular and systemic function. Therefore, this study potentially supports administration of pravastatin at night time to eliminate these problems and achieve better results than when administered in the morning. The overall 
results of the study are in accordance with clinical reports indicating that the evening administration of simvastatin, one of the most widely used statins, significantly reduces the night time rise in cholesterol level and modifies the diurnal rhythm of cholesterol biosynthesis in patients with familial hypercholesterolemia. ${ }^{34,35}$ These results could provide support for the present study.

The relationship between circadian rhythms and antioxidant enzyme levels is presently the subject of numerous investigations. An experimental study in young female rhesus monkeys has demonstrated a well defined circadian rhythm in erythrocyte superoxide dismutase activity, with a maximum at 10 am and a minimum at 10 pm. ${ }^{36}$ However, neither glutathione peroxidase nor glutathione reductase enzymes demonstrated any significant circadian changes, in contrast with superoxide dismutase. This study suggests that the diurnal changes in superoxide dismutase activity correlate closely with diurnal changes in plasma cortisol and dehydroepiandrosterone levels, ie, increases in the morning and decreases in the evening. The discrepancy seen between the circadian activity in that study and our study could reflect the difference in species studied as well as the model used in the study. The study done in monkeys suggests a correlation between the circadian rhythm of corticosteroid and superoxide dismutase activity, based on an aging factor. It reported that circadian rhythms in superoxide dismutase, cortisol, and dehydroepiandrosterone levels were smoothed out, while the correlation between diurnal changes in cortisol and superoxide dismutase were maintained, even in aged animals.

In contrast, a clinical study compared the circadian periodicity of plasma lipid peroxide levels and superoxide dismutase, catalase and glutathione peroxidase activity between 50 patients with pulmonary tuberculosis aged 21-45 years and 60 age-matched healthy volunteers, with diurnal activity from 6 am to about $10 \mathrm{pm}$ and nocturnal rest. ${ }^{37}$ The results showed marked circadian variation in plasma lipid peroxide levels in both the healthy subjects and the patients with pulmonary tuberculosis. Furthermore, a statistically significant difference was found in circadian rhythm for superoxide dismutase, catalase, and glutathione peroxidase activity between the normal volunteers and the patients with pulmonary tuberculosis. The activity of the antioxidant enzymes studied was found to be decreased at all sampling times during a 24-hour sleep-awake period in the patients, in contrast with their healthy counterparts. The midline estimating statistic of rhythm and circadian amplitude also decreased markedly. The study concluded that the decreased antioxidant enzyme activity in patients with pulmonary tuberculosis may have been associated with oxidative stress and/or decreased antioxidant defense mechanisms. This study could support the circadian variation in enzyme activity reported in the present work.

In conclusion, administration of a single oral daily dose of pravastatin to cholesterol-fed rabbits at night time achieved a better reduction in plasma total cholesterol levels, augmented superoxide dismutase enzyme activity, reduced TBARS content in liver homogenates, and increased catalase and glutathione peroxidase enzyme activity to a greater extent than morning administration of the same dose of pravastatin over a period of 8 weeks. This interesting finding of chronotherapy with pravastatin could be valuable in determining the proper timing of administration of the drug, thus achieving optimal hypolipidemic and antioxidative results.

\section{Acknowledgment}

This research was done under the auspices of the Medical Research Service of the Ain Shams University, and was supported financially by the Department of Pharmacology, Faculty of Medicine, Ain Shams University, Cairo, Egypt.

\section{Disclosure}

The author reports no conflicts of interest in this work.

\section{References}

1. Getz GS. An overview of atherosclerosis: A look to the future. Toxicol Pathol. 1990;18:623-635.

2. Bierman EL, Oram J, Mendez A. HDL receptor-mediated cholesterol efflux from cells and its regulation. Adv Exp Med Biol. 1991;285: $81-83$.

3. Sato R, Goldstein J, Brown M. Replacement of serine- 871 of hamster 3-hydroxy-3-methylglutaryl-CoA reductase prevents phosphorylation by AMP-activated kinase and blocks inhibition of sterol synthesis induced by ATP depletion. Proc Natl Acad Sci U S A. 1993;90: 9261-9265.

4. Miller FJ Jr, Gutterman DD, Rios CD, Heistad DD, Davidson BL Superoxide production in vascular smooth muscle contributes to oxidative stress and impaired relaxation. Circ Res. 1998;82: 1298-1305.

5. Souza H, Zweier J. Free radicals as mediators of inflammation in atherosclerosis. In: Parnham MJ, editor. Progress in Inflammation Research. Basel, Switzerland: Birkhäuser Verlag; 2001.

6. Sato J, Mohácsi T, Noel A, et al. In-vivo gene transfer of endothelial nitric oxide synthase to carotid arteries from hypercholesterolemic rabbits enhances endothelium-dependent relaxations. Stroke. 2000;31:968.

7. Ping-Sun Y, Zhu B, Browne A, et al. Nicotine does not influence arterial lipid deposits in rabbits exposed to second-hand smoke. Circulation. 2001;104:810.

8. Brown A, Bakker-Arkema R, Yellen L, et al. Treating patients with documented atherosclerosis to National Cholesterol Education Program-recommended low-density-lipoprotein cholesterol goals with atorvastatin, fluvastatin, lovastatin and simvastatin. J Am Coll Cardiol. 1998;32:665-672.

9. Brown M, Goldstein J. A receptor-mediated pathway for cholesterol homeostasis. Science. 1986;232:34-47. 
10. Grundy S. Cholesterol management in high-risk patients without heart disease. When is lipid-lowering medication warranted for primary prevention? Postgrad Med. 1998;104:117-120.

11. Endres M, Laufs U, Huang Z, et al. Stroke protection by 3-hydroxy-3methylglutaryl (HMG)-CoA reductase inhibitors mediated by endothelial nitric oxide synthase. Proc Natl Acad Sci U S A. 1998;95:8880-8885.

12. Jones P, Schoeller D. Evidence for diurnal periodicity in human cholesterol synthesis. J Lipid Res. 1990;31:667-673.

13. Otani M, Yamamoto M, Harada M, Otsuki M. Effect of long- and short-term treatments with pravastatin on diabetes mellitus and pancreatic fibrosis in the Otsuka- Long-Evans-Tokushima fatty rat. $\mathrm{Br} J$ Pharmacol. 2010;159:462-473.

14. Plakogiannis R, Cohen H. Optimal low-density lipoprotein cholesterol lowering - morning versus evening statin administration. Ann Pharmacother. 2007;41:106-110.

15. Ueda Y, Kitakaze M, Komamura K, et al. Pravastatin restored the infarct size-limiting effect of ischemic preconditioning blunted by hypercholesterolemia in the rabbit model of myocardial infarction. J Am Coll Cardiol. 1999;34:2120-2125.

16. Halliwell B, Chirico S. Lipid peroxidation: Its mechanism, measurement, and significance. Am J Clin Nutr. 1993;57:715S-724S.

17. Fraga C, Leibovitz B, Tappel A. Lipid peroxidation measured as thiobarbituric acid reactive substances in tissue slices: Characterization and comparison with homogenates and microsomes. Free Radic Biol Med. 1988;4:155-161.

18. Bradford M. A rapid and sensitive method for the quantitation of microgram quantities of protein utilizing the principle of protein-dye binding. Anal Biochem. 1976;72:248-254.

19. Sinha KA. Colorimetric assay of catalase. Ann Biochem. 1972;47: 389-394.

20. Rotruck JT, Pope AL, Ganther HE, Swanson AB, Hafeman DG, Hoekstra WG. Selenium: Biochemical role as a component of glutathione peroxidase. Science. 1973;179:588-590.

21. Osborne J, Lento P, Siegfried M. Cardiovascular effects of acute hypercholesterolemia in rabbits: Reversal with lovastatin treatment. J Clin Invest. 1989;83:465-473.

22. Scalia R, Appel J, Lefer A. Leukocyte-endothelium interaction during the early stages of hypercholesterolemia in the rabbit: Role of P-selectin, ICAM-1, and VCAM-1. Arterioscler Thromb Vasc Biol. 1998;18: 1093-1100.

23. Verbeuren T, Jordaens F, Zonnekeyn L. Effect of hypercholesterolemia on vascular reactivity in the rabbit, I: Endothelium-dependent and endothelium-independent contractions and relaxations in isolated arteries of control and hypercholesterolemic rabbits. Circ Res. 1986;58: $552-564$.
24. Alberts A. Discovery, biochemistry and biology of lovastatin. Am J Cardiol. 1988;62:10J-15J.

25. Chong P, Kezele R, Franklin C. High-density lipoprotein cholesterol and the role of statins. Circ J. 2002;66:1037-1044.

26. Saito Y, Yoshida S, Nakaya N. Comparison between morning and evening doses of simvastatin in hyperlipidemic subjects: A double-blind comparative study. Arterioscler Thromb. 1991;11:816-826.

27. Kiortsis D, Giral P, Bruckert E, Turpin G. Factors associated with low compliance with lipid-lowering drugs in hyperlipidemic patients. J Clin Pharm Ther. 2000;25:445-451.

28. Alanaz F. Pravastatin provides antioxidant activity and protection of erythrocytes loaded primaquine. Int J Med Sci. 2010;7:358-365.

29. Manna SK, Zhang HJ, Yan T, Oberley LW, Aggarwal BB. Overexpression of manganese superoxide dismutase suppresses tumor necrosis factorinduced apoptosis and activation of nuclear transcription factor-kappaB and activated protein-1. J Biol Chem. 1998;273: 13245-13254.

30. Zhang XP, Lin Q, Zhou YF. Progress of study on the relationship between mediators of inflammation and apoptosis in acute pancreatitis. Dig Dis Sci. 2007;52:1199-1205.

31. Aprigliano I, Dudas J, Ramadori G, Saile B. Atorvastatin induces apoptosis by a caspase-9-dependent pathway: An in vitro study on activated rat hepatic stellate cells. Liver Int. 2008;28:546-557.

32. Kashiwagi Y, Fujimoto K, Iwakiri R, et al. Loss of diurnal variation in ornithine decarboxylase and apoptosis in small intestine of Mongolian gerbils. J Gastroenterol. 2000;35:434-440.

33. Ruifrok AC, Weil MM, Thames HD, Mason KA. Diurnal variations in the expression of radiation-induced apoptosis. Radiat Res. 1998;149: 360-365.

34. Pappu A, Illingworth D. The effects of lovastatin and simvastatin on the diurnal periodicity of plasma mevalonate concentrations in patients with heterozygous familial hypercholesterolemia. Atherosclerosis. 2002;165:137-144.

35. Wallace A, Chinn D, Rubin G. Taking simvastatin in the morning compared with in the evening: Randomised controlled trial. $B M J$. 2003;327:788.

36. Goncharova N, Shmaliy A, Bogatyrenko T, Koltover V. Correlation between activity of antioxidant enzymes and circadian rhythms of corticosteroids in Macaca mulatta monkeys of different age. Exp Gerontol. 2006;41:778-783.

37. Singh R, Singh RK, Tripathi A, et al. Circadian periodicity of plasma lipid peroxides and anti-oxidant enzymes in pulmonary tuberculosis. Indian J Clin Biochem. 2004;19:14-20.
Journal of Experimental Pharmacology

\section{Publish your work in this journal}

The Journal of Experimental Pharmacology is an international, peerreviewed, open access journal publishing original research, reports, reviews and commentaries on all areas of laboratory and experimental pharmacology. The manuscript management system is completely online and includes a very quick and fair peer-review system.

\section{Dovepress}

Visit http://www.dovepress.com/testimonials.php to read real quotes from published authors. 